\title{
Capitalismo, crises e conjuntura
}

Capitalism, crises, and conjuncture

\author{
Virgínia Fontes \\ Historiadora. PPG História UFF; EPSJV-Fiocruz e Escola Nacional Florestan \\ Fernandes-MST. Rio de Janeiro (RJ). Integra o NIEP-Marx/UFF, Brasil. \\ virginia.fontes@gmail.com
}

Resumo: Conferência pronunciada no $10^{\circ} \mathrm{Se}-$ minário Anual de Serviço Social - Estado e Seguridade Social no Contexto da Crise do Capital. Compartilhei a mesa com Sara Graneman, uma das maiores conhecedoras da seguridade social. Minha intervenção tentou responder a uma extensa pauta suscitada por Liduína Oliveira, realizando uma introdução à reflexão sobre capitalismo, crises e conjuntura brasileira. A correlação entre a situação brasileira e a seguridade social foi brilhantemente tratada por Sara Graneman.

Palavras-chave: Capitalismo. Crises. Conjuntura. Financeirização. História contemporânea.

\begin{abstract}
Conference given at the 10th Annual Seminar of Social Service - State and Social Security in the Context of the Capital Crisis. I shared the table with Sara Graneman, one of Social Security's greatest connoisseurs. My intervention tried to respond to an extensive agenda raised by Liduína Oliveira, reacting an introduction to the reflection on capitalism, crises and Brazilian conjuncture. The correlation between the Brazilian situation and social security was brilliantly treated by Sara Graneman.
\end{abstract}

Keywords: Capitalism. Crises. Conjuncture. Financialization. Contemporary history

\section{Capitalismo e crises}

$\mathrm{P}$ ara Marx, o modo de produção ou a forma de modo de ser histórico da vida social (Marx, 1978, p. 121) não pode ser apresentado como um "modelo", um esquema ou reduzido a fórmulas matemáticas. Ele é sempre uma totalidade de relações sociais, tecidas a partir do solo da reprodução da vida material, na estreita relação entre seres sociais e natureza. Um modo de produção somente se pode apreender como um complexo articulado e é integrado por outros complexos (Lukács, 2013, p. 201-251). Sua reprodução, sua continuidade, entretanto, não ocorre de forma linear. As sociedades não permanecem estáveis e idênticas, pois embutem tensões, deslocamentos, ampliações, modificações 
que, agregando novos elementos ao todo, são também por ele impulsionados, condicionados e, por vezes, atrofiados, tendendo à manutenção da forma dominante da existência social. Um modo de produção, uma forma de ser histórica é ao mesmo tempo a reprodução do velho e o pulsar incessante de possibilidades, derivadas das contradições que nele habitam (Fontana, 1998).

O capitalismo, ou a forma de ser histórica sob o domínio do capital, se apresenta a partir da necessidade abstrata da valorização do valor. A propriedade altamente concentrada de recursos sociais precisa converter-se em capital, extrair valor e valorizar-se. Essa é a necessidade de suas classes dominantes e ela é imposta a todos. Isso significa que, do ponto de vista da produção da vida material, massas crescentes de seres sociais devem estar em concorrência e aptas para assegurar a atividade concreta que permite valorizar o valor, isto é, o trabalho do qual se extrai mais-valor.

Em outros termos, a sociedade capitalista repousa sobre a produção incessante de necessidades, a partir da necessidade central do capital - a valorização do valor. Tais necessidades — quer emanem do estômago ou da fantasia — estão recobertas pela forma de coisas disponíveis como mercadorias. Desse ponto de vista, a sociedade capitalista atua suprimindo a liberdade e aprofundando o terreno da necessidade. A liberdade é o uso do tempo para além da necessidade, quando as necessidades fundamentais estão supridas. Um tempo livre pode ser o tempo da criação, da cultura, da arte, dos afetos. Na sociedade capitalista, o tempo é devorado para a maioria dos seres sociais. Devem ter a cada dia renovada a necessidade fundamental de assegurar sua subsistência, quer seja através de um emprego, quer seja através da venda da sua força de trabalho sob quaisquer condições. $\mathrm{O}$ tempo deixa de ser o compasso da vida para tornar-se a medida social da produção do valor ("tempo é dinheiro"); quanto mais tempo e mais trabalhadores disponíveis, maior a possibilidade da extração de valor e, por conseguinte, de valorização do valor.

A vida se torna crescentemente o tempo da venda de força de trabalho, ainda agravado pela rapina dos direitos (como aposentadorias, saúde, educação). Assegurar a própria sobrevida exige vender força de trabalho a cada dia mais tempo (maiores jornadas) e por mais tempo (sem aposentadorias). Liberdade? O tempo livre é o da reposição da capacidade de produção, a cada dia mais estreito 
e encolhido para as grandes maiorias. O tempo sem venda da força de trabalho não é livre: os que não conseguem vender sua capacidade criativa sequer podem suprir suas necessidades.

A produção incessante de necessidades (valorização do valor) não corresponde à produção da satisfação (os valores de uso socialmente definidos como necessários) ou da liberdade (a redução das necessidades fundamentais, sempre historicamente consideradas.

Esta é uma sociedade que produz recorrentemente crises, pelo fosso entre necessidades sempre renovadas por novas mercadorias e a impossibilidade concreta da satisfação sequer das necessidades essenciais pela grande maioria. A abundância se torna o seu contrário, a criação de lixo inútil, a pura devastação sem sentido, enquanto a população segue com seu tempo espoliado.

Crises de superprodução renovam a produção da miséria, pelo desemprego, pela destruição de bens de uso que não se converteram em mercadorias. A concorrência desenfreada entre capitais exacerba a tendência à redução dos lucros; a introdução de tecnologias tenta freá-la, através de massas ainda maiores de mercadorias produzidas com menor número proporcional de trabalhadores. $\mathrm{O}$ desemprego é crescentemente constitutivo dessa dinâmica social e vem sendo convertido em forma de exploração do trabalho sem a mediação contratual, sem direitos, sem limites de jornada de trabalho.

Mas também crises geradas pela destruição lucrativa, sendo as guerras o mais impactante exemplo, com uma indústria bélica que se expande em todas as direções: máquinas de guerra, saúde, informática, bioengenharias etc. (Chamayou, 2013). Crises pela imposição da substituição dos bens necessários já adquiridos, cuja redução do tempo de uso (Mészáros, 2002, p. 675-700) impele a uma eterna recaída no reino da necessidade. Crise ainda induzida pelos efeitos humanos devastadores que a concorrência acirrada gera, pela violência como modelo de existência. As crianças são educadas à competição, à guerra de todos contra todos, à fascinação diante das vitrines, transferindo as relações afetivas para a posse de coisas, esvaziando-se as relações humanas, que demandam tempo. Tempo sempre ocupado pela necessidade renovada de vender força de trabalho.

Essa é, pois, a sociedade da produção incessante da máxima desigualdade: quanto mais concentrados os recursos sociais de produção, mais é preciso ampliar 
a massa de trabalhadores a extrair valor, mais é impulsionada a devastação da natureza, vista como mera "externalidade", e não como o nosso ambiente e meio de vida fundamental.

Do ponto de vista social, tal existência assemelha-se a enorme mercado abarrotado de coisas compráveis, palpáveis (objetos) ou não (como o transporte, a saúde, o conhecimento, a arte). O mercado esconde as relações sociais que o sustentam: capitalismo é extração de valor dos trabalhadores e, para tanto, é preciso sempre mais trabalhadores, produzidos por processos permanentes de expropriação. Trata-se da produção incessante de seres sociais necessitados o suficiente para vender a força de trabalho. O capitalismo é a introdução do mercado no âmago do ser social, quando a própria força de trabalho se converte em mercadoria - mas essa imposição não é abstrata, ela resulta de uma relação social concreta, a expropriação. Através dela a qualidade propriamente humana (a capacidade de transformar socialmente a natureza e, ao longo desse processo, também transformar-se) converte-se em brutal necessidade, $a$ da venda de seu tempo, de sua energia, de sua força de trabalho. Essas expropriações são a condição social para a extração de valor e para a valorização do valor. O outro polo dessa relação social é a concentração da riqueza, realizada através de roubos, saques, dívidas públicas e aprofundada através da extração contínua do mais-valor de massas crescentes de trabalhadores. A força de trabalho é o núcleo central da valorização do valor. Não obstante, é possível deslocar riqueza já produzida, através da especulação, das fraudes, por exemplo. É possível ainda capturar a riqueza produzida e economizada pelos trabalhadores, como seus fundos de pensão e reservas para aposentadoria, ou apoderar-se dos recursos públicos sob custódia do Estado, como seguridade, saúde e educação. Na atualidade, o capital vem empenhando o tempo futuro da força de trabalho, capturando agora o mais-valor ainda a ser produzido no futuro, em especial através das dívidas públicas. As expropriações se mesclam com a extração de valor.

Boa parte das expropriações e rapinagens nasceu com o capitalismo - a dívida pública é uma delas. Outras, mais recentes, resultam da enorme pressão de enormes massas de capitais concentrados e que buscam valorizar-se por todos os meios. Novas expropriações comprometem a vida humana, como a das águas. A valorização do capital, entretanto, não é jamais suficiente, pois resulta 
em massas de capitais maiores ainda, buscando valorização... e promovendo mais extensas e mais profundas expropriações da vida social.

Uma certa economia - dominante — se disfarça de ciência "natural" para abordar os seres sociais como unidades fragmentadas, tanto coletiva quanto singularmente, expropriando ("abstraindo") suas características fundamentais até reduzi-los a montantes comparáveis (números, quantidades). A racionalidade humana é reduzida a cálculo, a uma relação custo-benefício. Tudo deve ser expropriado, fragmentado e tornar-se comensurável (terra, ar, água, direitos, afetos, amores), sobretudo tudo o que reduza a "necessidade" do trabalhador de vender sua força de trabalho, isto é, tudo aquilo que permitiria vislumbrar um alento de liberdade para além do mercado...

Reencontramos a crise em dramáticos aspectos. Uma permanente crise psíquica, pois os seres sociais gastam o mais precioso de suas vidas, o tempo e sua capacidade de criação (o que nos permitiu a humanização), em atividades alienadas e embrutecedoras. O escasso tempo "livre" que resta, suficiente apenas para garantia do retorno ao trabalho, é alvo do capital, através do embrutecimento pela TV, pelas drogas, pela violência de cidades construídas contra os trabalhadores. Frustração reiterada dia após dia, o único mecanismo de escape é o que lhes aprisiona, o consumo. Na medida em que parcela expressiva da produção científica se converte em braço pesquisador para o capital - e não para a humanidade - , outras formas de suprimir a liberdade e convertê-la em necessidade estão em curso. Pesquisas recentes procuram expropriar o que parecia a última barreira, a única "condição natural" ineliminável pelo capitalismo, o sono, através de pesquisas científicas voltadas para "reduzir a necessidade de sono do corpo". O Pentágono, através da Darpa, pretende criar "um soldado sem sono", e cientistas realizam "testes experimentais de técnicas de privação de sono em diversos laboratórios, incluindo substâncias neuroquímicas, terapia genética e estimulação magnética transcraniana" (Crary, 2014, p. 7 e 42).

Crise, ainda, pela ruptura do sociometabolismo existente entre o ser social e a natureza, gerando devastação do ambiente necessário à existência, expropriando as águas (doces e salgadas), a qualidade do ar, a possibilidade da reprodução das sementes com as quais as sociedades se alimentaram através dos séculos (arroz, milho, soja, trigo). Novas biotecnologias produzem sementes estéreis 
(Terminator), cujos frutos não mais se multiplicarão, devendo ser recompradas a cada safra.

Pensar as formas da crise contemporânea exige recuperar as determinações mais significativas da vida crítica em que a humanidade foi lançada com a generalização do capitalismo. A crise atual incorpora novos elementos, mas se insere numa longa trajetória cuja compreensão pode evitar análises unilaterais que resultem em falsos remédios, como calmantes contra a ansiedade produzida pelo estresse dessa existência.

As crises são a marca genética do capitalismo, ele as agudiza. As crises sociais, econômicas, políticas, ambientais, humanas etc. não são suficientes para a superação do capitalismo. É necessário transformar a forma de ser social, alterar profundamente a relação entre os próprios seres sociais e entre nós e a natureza. É preciso enfrentar o capitalismo.

Uma última faceta das crises merece menção. É o uso da crise como chantagem política. Ela unifica grandes proprietários, partidos políticos pró-capital, entidades sem fins lucrativos sustentadas por corporações, grandes burocracias como os Bancos Centrais, e setores ligados às entidades econômicas internacionais, como Fundo Monetário Internacional ou Banco Mundial. Ameaçando com as crises que elas próprias promovem, burguesias altamente concentradoras de riquezas vêm extorquindo direitos, expropriando novas parcelas da vida humana e social, impondo a própria crise "como modo de governo" (Dardot e Laval, 2016, p. 310).

\section{Algumas características contemporâneas - a financeirização}

Há diversas maneiras de definir em que consiste a financeirização contemporânea, mas este espaço não comporta tais debates. De maneira sucinta, partiremos de Marx e Lênin, evitando meramente repeti-los, procurando apreender o período atual, no qual a escala da concentração supera o que puderam observar. Há, portanto, novas determinações que nos cabe identificar.

Marx (1985-6, Livro 3, cap. 21) alerta para a tendência capitalista à concentração da "pura propriedade", resultado da própria expansão do capitalismo 
e de sua aproximação com as formas bancárias e creditícias. Trata-se da concentração da propriedade de capital sob a forma dinheiro, que resulta da concentração propriamente capitalista. Essa propriedade - capital monetário ou capital portador de juros - representa quantidades vultosas de trabalho morto momentaneamente sob a forma dinheiro e distancia-se do processo direto de extração de valor, a cargo dos capitalistas funcionantes. Estes, os controladores (ou proprietários) dos meios de produção, estão subordinados à pura propriedade, embora compartilhem plenamente seus valores. Ao mesmo tempo, os extratores de valor são poderosamente impulsionados a ampliar as modalidades de subordinação dos trabalhadores e ampliar as massas de mais-valor extorquidas.

Lenin analisou diretamente o salto na escala de concentração de capitais no período posterior a Marx, que segundo ele teria modificado o próprio capitalismo, convertendo-o em imperialismo. Como Marx, ele também observa, dentre outras características, a separação crescente entre a propriedade do capital e a gestão empresarial. Do ponto de vista que estamos tratando, Lenin destaca a

união pessoal dos bancos das grandes empresas industriais e comerciais, a fusão de umas e de outras pela aquisição de ações, pela entrada dos diretores de banco nos conselhos de controle (ou de administração) das empresas industriais e comerciais e vice-versa. Essa "união pessoal" se completava pela] [...] "união pessoal" de ambas com o governo. [...] Disso resulta, de um lado, uma fusão cada vez mais completa... (Lenin, 1975, p. 58-62; grifos meus)

Se já era impactante em 1916, ano em que foi redigido o livro de Lenin, da Segunda Guerra Mundial para os dias de hoje, a escala da centralização e da concentração de capitais envolveu o que proponho chamar de uma fusão pornográfica entre os diversos setores do capital. Existem diferenças entre as atividades dos diversos setores do capital: o industrial, que envolve os procedimentos diversos de extração de valor e não se limita a unidades fabris, abrangendo processos de industrialização dos serviços; o bancário (creditício) e o comercial. Os processos de fusão e aquisição pelos maiores conglomerados e por grandes proprietários vêm dificultando separar de maneira precisa tais setores. Os grandes proprietários de capital atuam, através de holdings proprietárias, em praticamente todos os setores, nem sempre de forma direta, mas 
sempre impulsionando e pressionando pela extração máxima de valor no mais curto intervalo de tempo.

Marx e Lenin insistem que não devemos separar a forma abstrata da propriedade dos processos concretos de expansão e reprodução ampliada do capital. A financeirização não deve ser considerada como uma potência do dinheiro, isolada dos processos de extração de valor. Embora aumente a distância entre tais proprietários, a "pura" propriedade e a extração de valor estão intimamente ligadas. Ainda que os bancos assumam papel crucial, dinheiro não se reproduz sozinho, e os bancos precisam impulsionar a extração de valor dirigida por capitalistas funcionantes, aumentando a cota destinada aos bancos, qualquer que seja a escala de concentração/centralização dos capitalistas funcionantes. Decerto, crescem os procedimentos fraudulentos, a especulação e o capital fictício, mas todos seguem estreitamente ligados a essa contraditória correlação entre "pura propriedade", extração do valor e expropriações. Podemos observar isso no dia a dia contemporâneo, com a rapinagem sobre os direitos dos trabalhadores e sobre os fundos públicos. Paralelamente, crescem os processos de industrialização de novos setores (em especial a educação, a saúde e os transportes), extraindo valor em proporções gigantescas de trabalhadores com escassíssimos direitos ou mesmo sem nenhum direito, como é o caso do Uber.

Uma dificuldade suplementar é que, mesmo com essas expropriações de contratos e usurpações de recursos públicos, as taxas de lucro não parecem retornar aos índices considerados pelos capitalistas como necessários. Acumulam-se mais capitais pressionando por valorização (extração de mais-valor), o que tendencialmente aumenta a concorrência intercapitalista e interimperialista. A humanidade já enfrentou duas guerras mundiais em razão desse tipo de pressão concorrencial, que resultaram em furiosa destruição de forças produtivas: vidas humanas, bens materiais, cidades e países inteiros devastados. A produção foi direcionada totalmente para a destruição, para armamentos diversos, cuja utilidade é destruir-se e destruir a natureza, os seres humanos e suas obras. Terminadas as guerras, não se interrompeu a lucrativa produção bélica. Os lucros são garantidos para as empresas privadas da guerra, pois os maiores compradores são os Estados nacionais. A indústria bélica abrange na atualidade da siderurgia à aviação, da química à biofísica, dos nanomateriais à informática. Em suma, atinge praticamente todos os setores da produção e da vida social. 
A destruição (ou a queima) dos capitais excedentes constitui uma das formas trágicas de superar as crises e manter o capitalismo. No entanto, nas últimas grandes crises econômicas, em lugar de quebras dos bancos, de grandes prejuízos empresariais, os Estados assumiram os custos das crises geradas pelo grande capital, como os Estados Unidos após 2008 e os Estados europeus após 2012. As dívidas públicas ascenderam a cifras astronômicas e através delas se recosturam estreitos compromissos entre os Estados e o grande capital, lançando o custo sobre as populações. Acirram-se contradições de diversas ordens no cenário internacional, contradições essas derivadas de: extrema concentração e centralização do capital contraposta à pauperização absoluta e relativa de enormes parcelas da população; entre a socialização internacional dos processos de produção e a centralização estreita da grande propriedade dos recursos sociais de produção em poucas mãos e em pouquíssimos Estados; entre grandes proprietários buscando valorização acelerada, levando a tensões crescentes inter-imperialistas; da expropriação acelerada sobre a natureza e sua devastação, aprofundando ainda mais a concentração da riqueza e a produção da miséria; do crescimento das classes trabalhadoras e das formas brutais de fragmentação e opressão.

\section{Brevíssima menção ao Estado}

Sociedades de classes segregam o Estado, e o capitalismo não é exceção. O Estado capitalista tem configuração própria, distinta de outros períodos históricos, e sua apreensão é complexa, pois não é estático. Precisamos compreendê-lo como a forma pela qual a dominação de classes e suas contradições, concretamente presentes na vida social, são apresentadas como se fossem naturais. Suas características dependem da correlação de forças entre as classes e do regime político implementado. Nos limitaremos aqui ao regime representativo, formalmente democrático. A análise do Estado exige apreender dois momentos inseparáveis, cuja distinção é apenas formal, e se expressam na unidade da sociedade civil e da sociedade política. No primeiro, o Estado se apresenta como espaço de manifestação, de encaminhamento político, prometendo e/ou assegurando conquistas por dentro da ordem (como já mostraram Marx e Florestan Fernandes), 
consolidando direitos reivindicados pela população ou parcelas dela. Nesses termos, o Estado se apresenta como uma enorme conciliação das contradições sociais, garantidor da permanência das relações sociais fundamentais - o próprio capitalismo - , visando assegurar a reprodução do conjunto dessas relações sociais. Esse momento envolve desde a conciliação entre os diversos setores concorrentes das classes dominantes até a contenção das lutas sociais reivindicativas, encaminhando-as para conquistas parciais, mantida a subordinação de classes. As diferenças e divergências no amplo espectro da vida social, expressas nas entidades da sociedade civil, como os partidos, mídias, movimentos sociais, associações etc., convertem (ou não) seus programas em legislações e direitos que podem abranger toda a população - como educação, saúde e previdência públicas, por exemplo. No segundo momento, o Estado é a instância social de coerção, da violência física e da disseminação da violência simbólica, pela qual se eludem os interesses contraditórios antagônicos em nome de uma unidade estatal inflexível, rigorosa e punitiva. Exércitos, polícias e o conjunto das práticas judiciárias (inclusive o encarceramento) atuam paralelamente aos momentos de convencimento, bloqueando determinadas reivindicações no nascedouro ou estabelecendo seus limites. Tais procedimentos são naturalizados pela suposição de que o conjunto variado de tais violências responderia unicamente às "leis", legitimando-os. Os papéis coercitivo e "educador" do Estado se confundem. Sua plena consecução supõe certo grau de autonomia para que o Estado assegure a amplitude de funções contraditórias que deve realizar.

Como o Estado nasce da desigualdade fundamental no terreno da produção da vida — as classes sociais — que ele próprio precisa reproduzir e assegurar, ele permanentemente tensiona a igualdade jurídica infringida pela desigualdade real. Ademais, a "razão do Estado" se confunde com os interesses das burguesias - em especial o crescimento econômico, equiparado à produção capitalista.

A definição que melhor permite uma apreensão dinâmica do Estado capitalista talvez seja a formulada por Poulantzas (1981, p. 162), a partir das reflexões gramscianas: o Estado é a condensação material de relações de força entre classes e suas frações. É sempre espaço de dominação $e$ de luta de classes, cujos enfrentamentos geram movimentos internos ao Estado, eventuais conquistas ou derrotas pelas classes trabalhadoras ou subalternas. 
Essa correlação de forças depende de condições históricas nacionais, de conquistas mais ou menos asseguradas e de sua duração; de uma adesão das massas de trabalhadores nacionais às conquistas, opções e limites historicamente construídos, assim como a capacidade de assegurar tais conquistas frente às classes dominantes. Gramsci ajuda a compreender as formas de ampliação do Estado e sua estreita correlação com os aparelhos privados de hegemonia, tanto os procedentes de iniciativas das classes dominantes, quanto aqueles originários dos setores populares, ainda que mantendo uma implantação subalterna.

As últimas décadas vêm se caracterizando por uma tendência em escala internacional (mas ela não é homogênea e não ocorre identicamente em todos os estados capitalistas) à eliminação de conquistas dos trabalhadores e redução dos direitos populares nos Estados.

Outro elemento do Estado, também contraditoriamente resultado de lutas, conquistas e derrotas populares, é seu âmbito "nacional". Esta é uma longa e rica discussão, mas não temos tempo de suscitá-la, bastando para nosso intuito lembrar mais um de seus movimentos contraditórios. Por um lado, o Estado nacional (ou plurinacional) resulta de, e produz, laços sociais fortes (línguas, culturas, experiências, lutas, formas políticas) além de lastrear, na sociedade capitalista, a estrutura produtiva. Por outro lado, age para conter as massas trabalhadoras no interior de fronteiras estatais, procurando impedir lutas comuns de trabalhadores no âmbito internacional, renovando xenofobias e aprofundando discriminações e opressões.

Dentre as contradições crescentes nos Estados capitalistas na atualidade figura uma profunda desqualificação das formas políticas clássicas. A extrema concentração da propriedade dos recursos sociais de produção, protegida por legislações e entidades internacionais, acrescida de enorme volume (nacional e internacional) de aparelhos privados de hegemonia sustentados pelo empresariado e voltados para convencimento de massa, contando com recursos técnicos refinados, parece alterar a própria dinâmica da representação política.

As contrarreformas aceleradas para intensificar a extração de valor, em países do centro ou das periferias, realizadas muitas vezes por partidos de origem popular, aprofundam o descrédito da política. O aumento da violência e da coerção estatais, com maior repressão e militarização da vida social, configura 
crescentes situações de exceção (Agamben, 2004). A alegação de razões de segurança ("contra o terrorismo") se traduz por controlar todos os aspectos da vida, do trabalho ao cotidiano, como vasculhar passageiros em aeroportos, estações de trens, ônibus ou estádios, banalização de controles eletrônicos dispostos em prédios ou ruas, censura telefônica ou da correspondência, em alguns casos realizados em escala internacional e sobre praticamente toda a população, como denunciado pelo wikileaks. Sem falar de sua banalização, como o controle dos programas e plataformas de internet sobre o conjunto e o perfil de seus usuários. Longe de aumentar a segurança da vida humana, aprofundam as formas de violência direta e simbólica no cotidiano social.

A crise das formas parlamentares, ao lado da exacerbação securitária, abre brechas para a reemergência de belicosas direitas, carreando xenofobias, racismos, sexismos, além de pregar abertamente o aprofundamento das desigualdades nacionais e internacionais. A crise contemporânea assume, pois, um perfil político. As políticas públicas parecem bifurcadas: de um lado, asseguram com vigor a expansão do capital, através da implantação de barreiras protetoras, ou "blindagens" (Demier, 2017), isolando-as contra as expressões do voto popular.

Do outro lado, o desmantelamento das políticas universais e igualitárias. O conjunto desse processo, em curso na atualidade, é enorme desafio e exige o permanente exercício de pesquisas rigorosas e da elaboração de sínteses correlacionando as tensões nacionais e internacionais, do ponto de vista dos trabalhadores. As grandes contradições - e crises - atuais emergem diretamente da expansão do capitalismo e de seu ideário liberal ou neoliberal, e não do enfrentamento de processos revolucionários. Não obstante, um anticomunismo ferrenho e retrógrado é reativado, aparentemente pretendendo bloquear qualquer reivindicação de cunho igualitário. Em suma, a democracia parece ter se tornado comunista.

\section{Algumas linhas sobre a conjuntura brasileira}

O Brasil do século XXI é um país capitalista, cuja população foi majoritariamente expropriada, dependendo do mercado para vender força de trabalho e subsistir. As parcelas da população rural brasileira subsistentes vêm sendo 
submetidas a sucessivas violências, chacinas, envenenamentos, enquanto prosseguem as expropriações sobre os camponeses e os indígenas. Falamos de uma das grandes economias do planeta, em tamanho do PIB, onde figura entre as dez maiores. ${ }^{1}$

A proteção da grande propriedade dos recursos sociais de produção é assegurada, enquanto a população é espoliada. Os grandes proprietários dos títulos da dívida pública têm seus lucros futuros garantidos, transferindo-se para o capital no presente o mais valor a ser extraído no futuro.

Um governo de partido de origem popular - o Partido dos Trabalhadores - PT - chegou ao governo, mas prosseguiu e aprofundou as contrarreformas, procurando contrabalançá-las com programas efêmeros para minorar o sofrimento dos setores sociais mais frágeis. Governando através de uma peculiar conciliação de classes, garantindo gigantescos ganhos para os grandes conglomerados e parcas melhorias para os setores populares, acenou uma "imagem" democrática, enquanto fomentava o descrédito popular na política.

Foi apeado de maneira ilegítima do poder, e não pelos bem ou malfeitos que porventura tenha cometido. A razão foi chantagista: o PT não quis ou não conseguiu interromper uma operação judicial — Lava-Jato — que, direcionada contra ele próprio, começava a correlacionar parlamentares a recursos de propinas de empresas públicas e privadas. Paradoxalmente, sua destituição encontrou decidido apoio dos mesmos setores empresariais que o PT favoreceu, os quais louvavam a Lava-Jato enquanto procuravam dela se proteger (não queriam "pagar o pato"). Fartos recursos empresariais (nacionais e estrangeiros) irrigaram organizações de extrema direita, promovendo manifestações públicas de setores de classe média, chegando a reivindicar a ditadura, além de exibirem sem pejo facetas racistas, sexistas e discriminatórias. Uma democracia burguesa esquálida era apresentada como se fosse comunismo, e as declarações de voto de muitos parlamentares durante o impeachment envergonharam até mesmo muitos dos que o apoiavam, a começar por jornalistas da grande mídia.

1. O grupo das quinze maiores economias: EUA, China, Japão, Alemanha, Reino Unido, França, Brasil/ Itália, Índia, Rússia, Canadá, Coreia do Sul, Espanha, México, Indonésia. Disponível em: <http://www.funag. gov.br/ipri/images/analise-pesquisa/tabelas/top15pib.pdf>. Acesso em: 5 maio 2017. 
Escancarava-se o já sabido: a peculiar seletividade do Estado brasileiro, no qual os interesses burgueses encontram acolhida, enquanto há renitente bloqueio à admissão das reivindicações populares. Tornaram-se públicos os estreitos laços entre partidos, instituições públicas, grandes empresas e aparatos diversos de organização empresarial. Todos os grandes partidos tradicionais foram atingidos: além do PT, o Partido do Movimento Democrático Brasileiro, o Partido da Social Democracia Brasileira, o Democratas - DEM, o Partido Popular - PP, dentre muitos outros. Os partidos que não participavam desses esquemas, especialmente da esquerda, estavam e seguem sob a ameaça de serem riscados dos pleitos, dado seu pequeno número de parlamentares. Alguns grandes empresários foram presos, negociando essa condição por delações dos demais.

Uma crise econômica - inicialmente de médias proporções — vem sendo aprofundada pela sequência de crises e golpes: institucional, política e, o mais importante, social, com milhares de desempregados. A violência do Estado cresceu de forma impactante nas últimas décadas. Ela se tornou mais evidente na truculência com que foram tratados manifestantes que ousaram criticar os descaminhos em curso, em 2013. Em 2017, essa violência continua a crescer e contou inclusive com o apelo às Forças Armadas e o uso indiscriminado de bombas químicas (de "efeito moral") e de armas letais contra manifestações pacíficas. Essa violência se acrescenta ao encarceramento massivo em condições desumanas, às torturas ainda corriqueiras em delegacias e carceragens, ao endurecimento legal e à criação e armamento de novas forças policiais. Mas não para por aí: milícias paramilitares controlam bairros populares, em estranho jogo com facções de tráficos diversos. Em conjunto, policiais, paramilitares e traficantes manietam a população desses bairros.

As contrarreformas iniciadas anteriormente se aprofundaram no (des) governo Michel Temer, apesar de sua gritante ilegitimidade. Elas se instauram como dupla garantia: intocabilidade da grande propriedade, por mais lesiva que seja à humanidade e à população (como latifúndios, patentes, papéis da dívida) e extorsão de direitos, rebaixando o valor da força de trabalho e assujeitando-a a piores condições de existência.

O voto popular é desqualificado por diversas formas. As propagandas políticas não se relacionam a programas e a posições sociais, mas resumem-se 
a marketing eleitoreiro. $\mathrm{O}$ custo das eleições distanciou os grandes partidos das bases populares, estreitando suas relações com o empresariado financiador de campanhas e comprador de "serviços" legislativos. O impeachment escancarou o problema: boa parte dos parlamentares, com denúncias de envolvimento em corrupção, apressou-se a prestar quaisquer serviços para adiar ou impedir seu próprio julgamento. Em primeiro lugar, repudiando o próprio voto popular e destituindo uma presidente, para atribuir a presidência a outro parlamentar sob suspeita. Em segundo lugar, ao abandonarem de vez quaisquer vínculos com os programas acenados quando das eleições. Passaram a assegurar apenas uma dupla fidelidade: aquela prestada ao grande empresariado, cujo apoio explicitamente depende de assegurarem a grande propriedade do capital (em especial a dívida pública) e de devastarem os cofres públicos e as conquistas populares. A segunda fidelidade é mais efêmera e vigora entre os parlamentares sob suspeição, procurando impedir o alcance da Lava-Jato e garantir suas reeleições. A grande mídia defende com unhas e dentes a expropriação em curso e, enquanto foi possível, equilibrou-se entre defender a Lava-Jato e procurar dispensar certa proteção a alguns parlamentares suspeitos, mas estratégicos, ao menos enquanto se desincumbiam das tarefas da violenta contrarreforma antipopular. Até quando essa mídia manterá a defesa da Lava-Jato? Até onde poderá acomodar os suspeitos de sua confiança?

A crise institucional se aprofunda, os partidos envolvidos, em especial os grandes, entram em crise. O conjunto da representação eleitoral cai sob profunda suspeição popular. Os partidos menores, de perfil ideológico, sobretudo à esquerda, voltam a aparecer nas telas de televisão, dentre os poucos sobre os quais não pairam suspeitas. São, entretanto, igualmente penalizados pela desconfiança generalizada sobre os partidos.

Tal crise expressa - mesmo se for pelo silêncio - crescentes tensões entre os setores dominantes, a começar pelas grandes burguesias. Não há espaço aqui para aprofundar o tema, mas vale sugerir que tais tensões podem se originar da escala de concentração de certos grupos, poderosamente beneficiados, contrapostos a outros grupos e setores que exigem uma partilha mais equânime do botim público; também podem encontrar fundamento nas modificações ocorridas nas últimas décadas nos processos de organização do grande empresariado. Elas hoje envolvem inúmeros níveis, a começar por sindicatos, 
federações e confederações, expandidas a partir da década de 1960 por inúmeras associações setoriais e ainda acrescidas, em especial a partir da década de 1990, por uma grande quantidade de fundações e entidades empresariais sem fins lucrativos. Todas elas se dedicam a conceber e formular políticas públicas variadas, indicam quadros "técnicos" para as diferentes instâncias do aparelho estatal, financiam partidos e fomentam certas diretrizes políticas, agindo muito além de seus setores específicos de atuação econômica.

Os setores populares, estudantes, os trabalhadores sindicalizados ou não, assistiram ao início da crise através das lentes do desencanto com a política. As reivindicações fragmentárias expressas por milhares de pessoas em 2013 não redundaram em novas organizações. Foram rapidamente do fascínio ao susto com as manifestações da direita, em 2015, que explicitamente os discriminava, culpando a pobreza e a democracia pela então incipiente crise econômica. A velocidade e a ferocidade dos ataques contra seus direitos realizados pelo (des)governo Temer, a exacerbação da violência estatal, além da disseminação de violências discriminatórias de todo o tipo fomentam a expressão de novas modalidades de luta social. A ordem existente está descomposta e não se ajeita com remendos.

Recebido em 7/6/2017 - Aprovado em 18/6/2017

\section{Referências bibliográficas}

AGAMBEN, G. Estado de exceção: Homo Sacer, II, I. São Paulo: Boitempo, 2004.

CHAMAYOU, G. Théorie du Drone. Paris: La Fabrique, 2013.

CRARY, J. Capitalismo tardio e os fins do sono. São Paulo: Cosac Naify, 2014. Agradeço a Sara Graneman a indicação desse livro.

DARDOT, P.; LAVAL, C. Ce cauchemar qui n'en finit pas. Paris: La Découverte, 2016.

DEMIER, F. Depois do golpe: a dialética da democracia blindada no Brasil. Rio de Janeiro: Mauad X, 2017. 
FONTANA, J. História: análise do passado e projeto social. Bauru: Edusc, 1998.

LENIN, V. I. L'impérialisme, stade suprême du capitalisme. Paris: Editions Sociales; Moscou: Editions du Progrès, 1975.

LUKÁCS, G. Para uma ontologia do ser social. São Paulo: Boitempo, 2013. v. 1.

MARX, K. Para a crítica da economia política. In: . Manuscritos econômico-filosóficos e outros escritos. São Paulo: Abril Cultural, 1978.

. O capital: crítica da economia política. 2. ed. São Paulo: Nova Cultural, 1985-6.

MÉSZÁROS, I. Para além do capital. São Paulo: Ed. Unicamp/Boitempo, 2002.

POULANTZAS, N. O Estado, o poder, o socialismo. Rio de Janeiro: Graal, 1981. 